\title{
The Politics of Water
}

\author{
Rose Cullis
}

Rose Cullis is a playwright living and working in Toronto. Her playwriting credits include Baal (Buddies in Bad Times Theatre, Toronto), Pure Motives (The Theatre Centre, Toronto), and That Camille Claudel Feeling (a danceltext performance piece presented as part of the Toronto Fringe Festival). She has collaborated with visual artists, dancers, and musicians in creating an installation piece for Shared Habitat - A Festival of Art and the Environment. Most recently she won an award fiom the Harold Greenberg Fund (script development program) to develop a screenplay of her play Baal. Her writing has appeared in UnderCurrents and The ChurchWellesley Review. She is a member of the Stern Writing Mistresses.

The house is leaking

A burst pipe here and then another

Soon the wood floors are thick as blotting paper I jam my finger into a hole in the pipe but it's not enough

water slips across boundaries, defies the rules of geography runs hidden and determined through deep veins - drops through the porous surface of the earth and creates underground rivers that swell into being over hundreds and hundreds of years

Look down:

Two women are in a boat headed for the shore Their paddles dip and rise and dip 


\section{$156 /$ Cullis}

Did you know our bodies are seventy percent water? she asks me her mouth soft and sweet and wet Her tongue it's her tongue I love, her tongue I sin with Wishing I could possess it, wishing I could make it all mine

We wanted to live as birds construct a tender house of straw accept the seasons of love the inevitable ebb and tide of our passion for one another make a sweet and temporary home rise together and fall apart willingly

to love in awareness

to drink deep and let go without a trace

We had a dream of free water

And this is the story:

that I feared thirst, I wanted power, I built dams, I held back floods, Grasped at what we had and turned it into a commodity I took our free gift our love and I made it A token for exchange to have and to hold

But love won't yield to that kind of tyranny

We can create a loss

by accounting for what we have in a particular way It's all too easy to take generations of rainwater and squander it to direct water into tubes that drip through a wash of poisons till the sea feels the gap in the earth demand a new weight, and presses in as salty as a lover's tear 
And they say that someday

wars will be fought over water

See how water can be made to yield to a kind of measure, it can be valued at so many dollars a litre, and sold and suddenly there isn't enough

How come some of us have it and some of us don't?

There are shells with pointed tips as delicate as nipples with bruised blue spirals as casual and precise as her fingers trailing a flesh-toned interior in my ear the pounding sea my crashing blood

Maybe if I had had love, I wouldn't have wanted it so badly

Coiled accounts of love lost who did what why make a labyrinthine vortex always partially filtered polluted by encounters water spinning down the drain into pipes spiked with poisons into combined sewers seasoned with waste till the whole frothing soup is either hurled into the closest body of water or filtered, treated, bleached and released

On the beaches in Toronto a sign reads "No Swimming" I stand on a rough shore wailing into the implacable waves A roar of sea rushes at me and stops then tries again

The water gleams like hammered metal 